\title{
Magnetic Properties of Zr/Ti Substituted Mn-Zn Ferrites
}

\author{
B. RAMESH, A.D.P. RAO', K. SAI LAKSHMI², P.R.M. RAO² AND S.B. RAJU
}

\author{
Department of Physics, 1Department of Nuclear Physics and 2Department of Inorg. \& Anal. Chemistry
} Andhra University, Visakhapatnam - 530003 , India.

\begin{abstract}
By substituting $\mathrm{Zr} / \mathrm{Ti}$ in the matrix of $\mathrm{Mn}-\mathrm{Zn}$ ferrites, $\mathrm{Tc}, \mathrm{Ms}, \mu_{i}, \mathrm{~K}, \mathrm{H}_{\mathrm{r}}$ and $\mathrm{P}_{\mathrm{h}}$ parameters are studied. The variations are explained on the basis of cation preferential sites and hence with the modified strength of exchange interactions of cations. Due to non-magnetic behaviour of the dopants, magnetic properties are decreased and the $\mathrm{H}_{c}$ values are increased. The hysteresis loss $\left(\mathrm{P}_{\mathbf{h}}\right)$ values are decreased with the substituent concentration increasing the quality of the material.
\end{abstract}

\section{INTRODUCTION}

Core loss is one of the major draw backs to use a ferrite in any device as core material. So it is necessary to reduce core losses of a ferrite material. The increase of operating frequency of Switching Mode Power Supplies (SMPS) reduces the size of SMPS. Recently these are being in use from $25 \mathrm{KHz}$ to several $\mathrm{MHz}$ [1]. $\mathrm{Mn}-\mathrm{Zn}$ ferrites are suitable to use as core material in the frequency range below $1 \mathrm{MHz}$. Recently efforts have been made to develop low power loss material by introducing a foreign cation in the matrix of a ferrite [2]. Substitution of high valency cation in the matrix of $\mathrm{Mn}-\mathrm{Zn}$ ferrite is expected to reduce the core losses and also alters the physical properties.

\section{Sample Preparation}

. Mn- $\mathrm{Zn}$ ferrites with the composition $\mathrm{Zn}_{0.37+x / 2}$

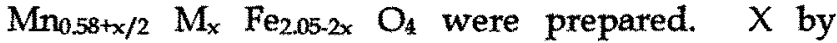
conventional double sintering method. Initial firing was done at $1000^{\circ} \mathrm{C}$ for 3 hrs. and then grounded using ball mill to obtain fine powder. Final sintering was done at $1200^{\circ} \mathrm{C}$ for 2 hours in air. X-ray diffractograms of all the materials were confirmed the single phase formation of cubic spinel The obtained lattice parameter $8.519 \AA$ is consistent with the reported [3] value 8.4998 $\AA$. Using the Laroia Sinha technique [4] the Curie temperature and with the technique explained by Heck [5], the initial permeability measurements were made. At room temperature hysteresis loops for all the materials were traced on applying field of $2.5 \mathrm{~K}$ Gauss at 50 $\mathrm{Hz}$ with high field loop tracer which was described earlier researchers [6]. Some of the loops are shown in the Fig.1. Grain size measurements were done using SEM and typical photographs are shown in Fig. 2. The results of Curie temperature (Tc), saturation magnetisation $(\mathrm{Mg})$, initial permeability $(\mu i)$, and grain size are tabulated in table 1 and Anisotropic constant(K), Coercivity $(\mathrm{Hc})$, remanence ratio $(\mathrm{Br} / \mathrm{Bs})$ and hysteresis losses $(\mathrm{Ph})$ are listed in the table 2.

\section{RESULTS AND DISCUSSION}

Due to non-magnetic behaviour of dopants, magnetic properties are influenced and the loss factor is reduced. The slight increase of $\mathrm{Tc}$ and Ms for 0.1 concentration of $\mathrm{Zr}$ doped ferrite can be explained with the modified strength of $A A, B B$ and $A B$ interactions assuming that $\mathrm{Zr}$ entering $\mathrm{A}$ sites. Consequently $A$ sublattice magnetisation reduces which inturn increases Ms. For further increase of $\mathrm{Zr}$ concentration, it occupies both tetrahedral (A) and octahedral (B) sites causing reduction in both $M_{A}$ and $M_{B}$. Hence the $M s$ continuously decreases upto $x=0.4$. It is note worthy that the $T c$ is not influenced significantly by dopant concentration from $x=0.2$ which can be understood interms of Curie constants $C_{A}$ and $C_{B}$ for $A$ and $B$ sublattices. The changes in $M_{A}$ and $M_{B}$ may cause $T c$ to be unaffected because of the dependence on both $\left(C_{A}+\right.$ $\left.C_{B}\right)$ and $\left(C_{A} C_{B}\right)$ as described by earlier scientists [7]. Recently Pal et al, [8] obtained same values of $\mathrm{Tc}$ $\left(385^{\circ} \mathrm{C}\right)$ for different concentrations of bismuth substitution in $\mathrm{Ni}-\mathrm{Zn}$ ferrites. The $\mathrm{Tc}$ and $\mathrm{Ms}$ for $\mathrm{Ti}$ doped ferrites are found to be decrease since $\mathrm{Ti}^{4+}$ ions prefer only the octahedral sites [9]. This reduces the $B$ sublattice magnetization resulting decrease of the net magnetisation. The variation trend of $\mu_{\mathrm{i}}$ with $\mathrm{x}$ seems to have correlation with the observed variation of Ms Vs $x$. However, for $x=0.1$ of $\mathrm{Zr}$ substituted ferrite $\mu_{\mathrm{i}}$ value does not reflect the Ms measurement which can be attributed to the rise of anisotropy constant $(K)$ thus reduces the value of $\mu_{\mathrm{i}}$. From the Table 1 it is observed that the grain size $(D g)$ value decreases with the dopant concentration. This reflects the decrease of magnetic properties and also the decrease of conductivity. The dopants are induced to form the oxygen rich layers at grain boundaries during sintering. This 
Table 1. Variation of magnetic properties with dopant concentrations

\begin{tabular}{cccccccccc}
\hline $\begin{array}{c}\text { Dopant } \\
\text { conc. }\end{array}$ & \multicolumn{2}{c}{$\mathrm{Tc}\left({ }^{\circ} \mathrm{C}\right)$} & \multicolumn{2}{c}{ Ms (Gauss) } & \multicolumn{2}{c}{$\mu_{\mathrm{i}} \times 10^{2}$} & \multicolumn{2}{c}{$\mathrm{Dg}(\mu \mathrm{m})$} \\
\hline $\mathrm{Zr} / \mathrm{Ti}$ & $\mathrm{Zr}$ & $\mathrm{Ti}$ & $\mathrm{Zr}$ & $\mathrm{Ti}$ & $\mathrm{Zr}$ & $\mathrm{Ti}$ & $\mathrm{Zr}$ & $\mathrm{Ti}$ \\
0.0 & 300 & 300 & 350 & 350 & 14.0 & 14.0 & 4.50 & 4.50 \\
0.1 & 335 & 260 & 420 & 230 & 9.0 & 8.0 & 4.10 & 4.15 \\
0.2 & 330 & 245 & 270 & 190 & 8.0 & 7.0 & 4.00 & 4.10 \\
0.3 & 330 & 225 & 230 & 170 & 7.5 & 6.5 & 3.75 & 4.15 \\
0.4 & 330 & 180 & 190 & 90 & 7.0 & 6.0 & 3.74 & 4.20 \\
\hline
\end{tabular}

Table 2. Variation of anisotropic constants, coercivity, remanence ratio and hysteresis loss with concentrations

\begin{tabular}{cccccccccc}
\hline $\begin{array}{c}\text { Dopant } \\
\text { conc. }\end{array}$ & \multicolumn{2}{c}{$\mathrm{K} \times 10^{3}$} & \multicolumn{2}{c}{$\mathrm{Hc}(\mathrm{Oe})$} & \multicolumn{2}{c}{$\mathrm{Br} / \mathrm{Bs}(\%)$} & \multicolumn{2}{c}{$\mathrm{P}_{\mathbf{h}}\left(\mathrm{mm}^{2} / \mathrm{g}\right)$} \\
\hline $\mathrm{Zr} / \mathrm{Ti}$ & $\mathrm{Zr}$ & $\mathrm{Ti}$ & $\mathrm{Zr}$ & $\mathrm{Ti}$ & $\mathrm{Zr}$ & $\mathrm{Ti}$ & $\mathrm{Zr}$ & $\mathrm{Ti}$ \\
0.0 & 7.35 & 7.35 & 0.62 & 0.62 & 16 & 16 & 14 & 14 \\
0.1 & 9.70 & 5.90 & 0.66 & 0.85 & 25 & 31 & 15 & 8 \\
0.2 & 7.00 & 4.70 & 0.90 & 0.90 & 33 & 28 & 8 & 6 \\
0.3 & 6.70 & 4.30 & 0.95 & 0.95 & 30 & 35 & 3 & 4 \\
0.4 & 6.70 & 3.70 & 1.00 & 0.96 & 31 & 39 & 3 & 2 \\
\hline
\end{tabular}

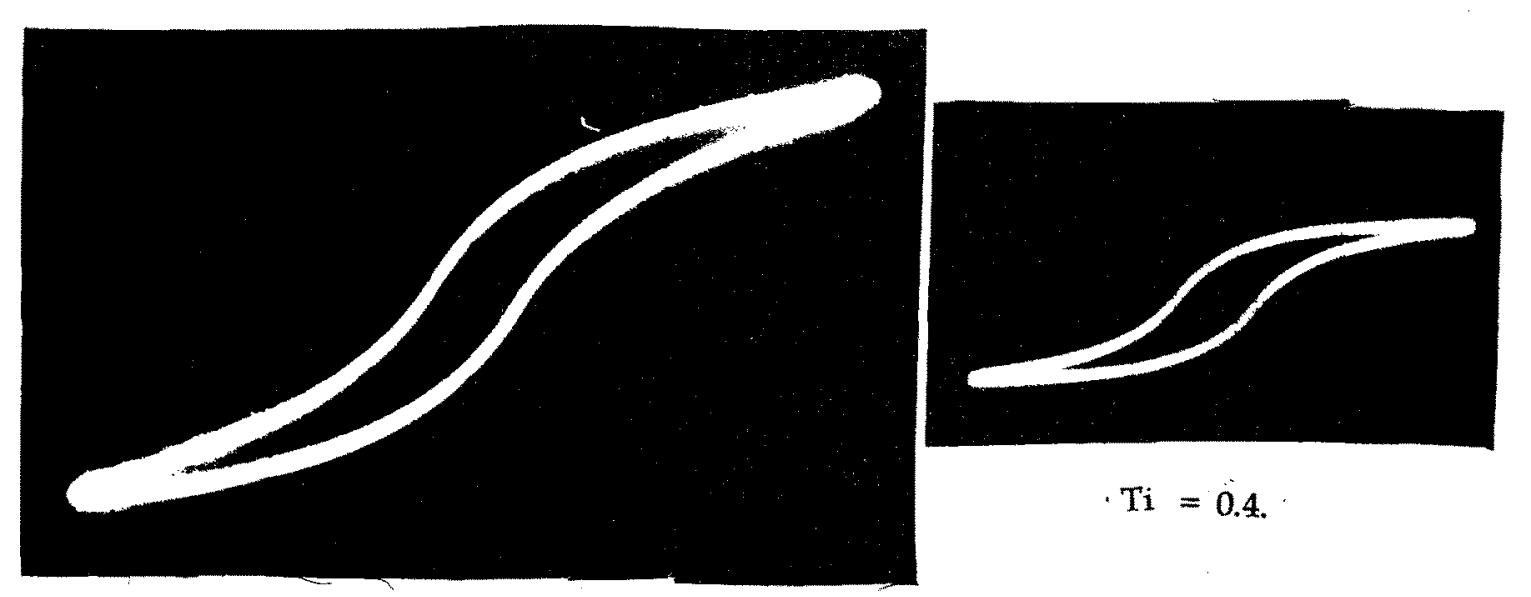

$\mathrm{Ti}=\mathrm{Zr}=0$

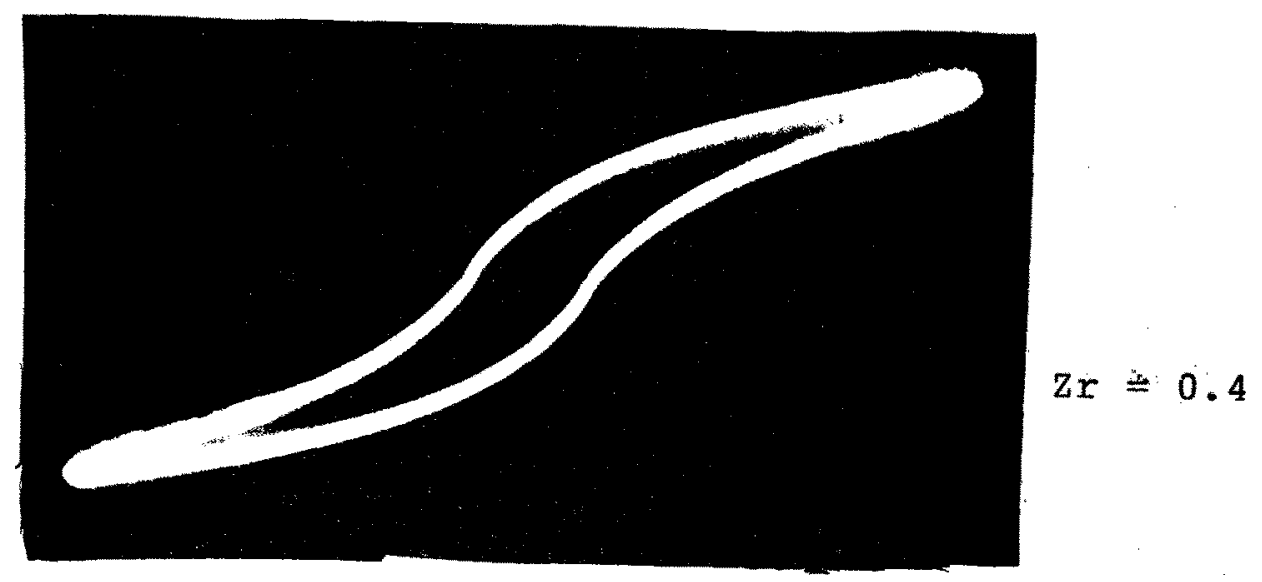

Fig. 1 Hysteresis loops for the system $\mathrm{Mn}_{0.58+x / 2} \mathrm{Zn}_{0.37+x / 2} \mathrm{M}_{x} \mathrm{Fe}_{2.05-2 \mathrm{x}} \mathrm{O}_{4}$. 
increases the grain boundary and thus grain size decreases.

The variation of $\mathrm{K}$ with $\times$ can be explained on the basis of the single-ion anisotropy model [10] in which $\mathrm{Fe}^{3+}$ ions present $A$ and $B$ sites contribute separately to the anisotropy energy. The observed Coercive field $(\mathrm{Hc})$ values are found to be increase with the concentration for both the dopants. Van dex Zaag et al., [11] reported that the value of $\mathrm{Hc}$ increases with the decrease of grain size and this dependence can be interpreted by assuming grain boundary with unit permeability which also accounts for the influence of the grain size on the $\mu_{i}$ of the same ferrite for smaller grains. In the present studies also materials with smaller grains the $\mathrm{Hc}$ values are increased as the $\mu_{i}$ values decreased and this can be accounted for the above phenomena. The ratio $\mathrm{Br} / \mathrm{Bs}$ does not show a systematic trend for both the series but the values are higher for higher concentrations of $\mathrm{Ti}^{4+}$ and $\mathrm{Zx}^{4^{+}}$. This means dopants are increased the value of residual magnetic induction in the substance when the applied field reduced to zero. This is probably related to the spin movement of the cations. The core losses of a power ferrite is sum of the hysteresis loss $\left(P_{h}\right)$, eddy current loss $(\mathrm{Pe})$ and dielectric loss (Pde). Area of a loop directly gives the hysteresis loss $\left(\mathrm{P}_{h}\right)$ contribution to the core losses. The observed $P_{h}$ values are found to be decrease and hence the quality of the material is increased. If the operating frequency of $\mathrm{Mn} \mathrm{Zn}$ ferrites is lower than the relaxation frequency of the domain wall displacement, the core losses is predominant. The hysteresis loss, $P_{h}=\int B d H$ which gives [12] the loop area measured under maximum flux density $(\mathrm{Bm})$ and depends on $\mathrm{Ms}, \mathrm{K}$, microstructure and magnetostriction $\left(\lambda_{\mathrm{s}}\right)$. Smaller grains increase resistivity and decrease the permeability with the increasing Coercive force.

\section{CONCUUSIONS}

1. Initially $\mathrm{Zr}$ enters into $\mathrm{A}$ sites resulting increase in $\mathrm{Tc}$ and $\mathrm{Ms}$.

2. Ti cation prefers B sites which causes reduction in magnetic properties.

3. Coercive field values are increased with the dopant concentration.

4. Hysteresis loss is reduced with the increase of dopant concentration which improves the quality of the material.

\section{REFERENCES}

[1] E. Otsuki, S. Yamada, T. Otsuka, K. Shoji and T. Sato, J. Appl. Phys. vol. 69 (8), pp. 5942-5944, 1991.

[2] C.S. Liu, J. M. Wu, C.J. Chen and M.J. Tung, J. Mag. \& Mag. Mater., vol. 133, pp. 478-480, 1994.

[3] K.H. Rao, N.K. Gaur, K. Agarwal and R.G. Mendiratta, J. Appl. Phys., vol 53 (2), pp. 1122-1126, 1982.

[4] K.K. Laroia and A.P.B. Sinha, J. of pure \& Appl. Phys., vol. 1, pp. 215-219, 1963.

[5] Heck. Dr. Ing. Carl. "Magnetic Materials and their applications”, Butterworths, London, 1974.

[6] A.M. Varaprasad and C.M. Radha Krishna Murthy, Bull. Mater., Sci., vol. 8, pp. 567-568, 1986.

[7] $\mathrm{Ch}$. Kittel "Introduction to solid state physics", Wiley estern Ltd, pp. 477-478, 1976.

[8] M. Pal, P. Brahma and D. Chakravorty, J. Mag \& Mag. Mater., vol. 152, pp. 370-374, 1996.

[9] R.C. Srivastava, D.C. Khan, A.R. Das and T.M., Srinivasan, proc. of ICF-V, pp. 359-364, 1989.

[10] A.B. V. Groeneu and A. Schulkes, J. Appl. Phys, vol. 38 (3) pp. 1133 - 1138, 1967

[11] P.J. Van der Zaag, M.T. Johnson, J.J.M. Ruigrok, C. Bordel and H.J. de wit, J. Mag \& Mag. Mater., vol. 129, pp. L 137- L140, 1994.

[12] A. Znidarsic, M. Limpel and $M$. Drofenik, IEEE Trans. Magn, vol. 31 (2), pp. 950-953, 1995.
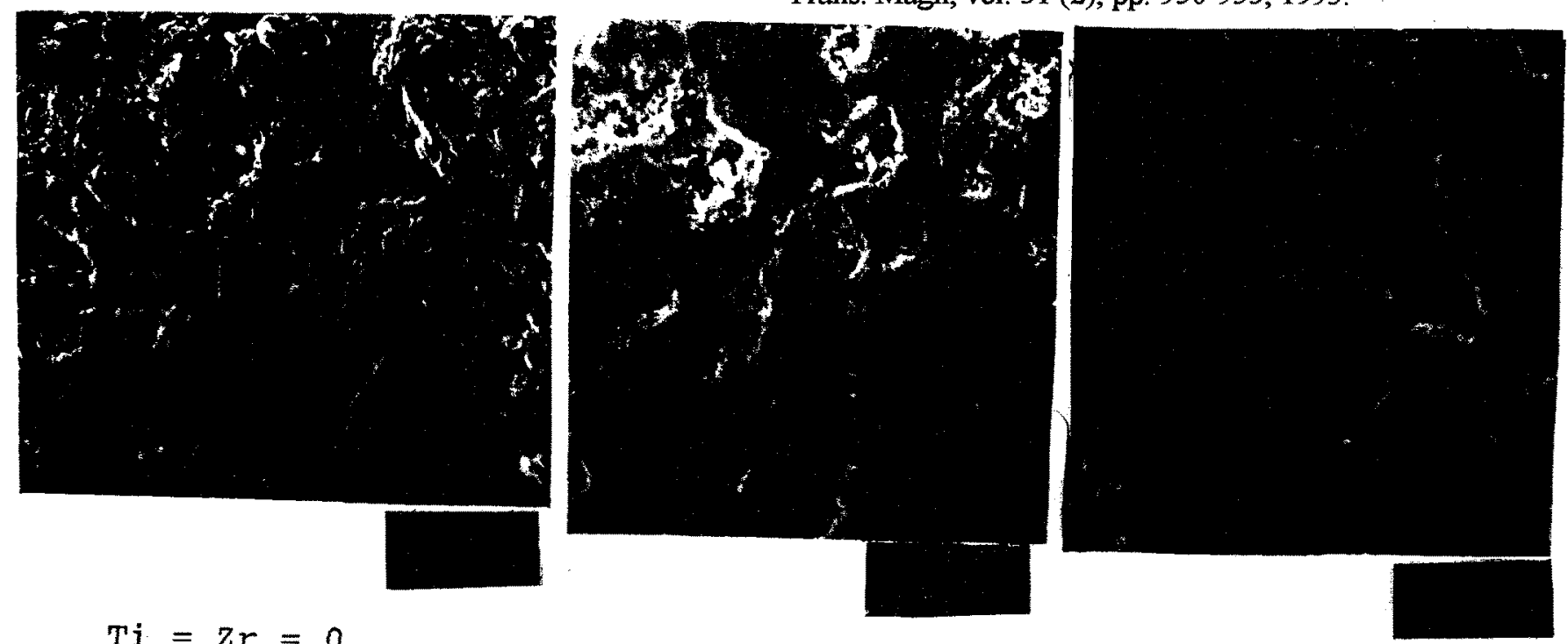

$\mathrm{Ti}=\mathrm{Zr}=0$

$$
\mathrm{Zr}=0.3
$$$$
\mathrm{T} i=0.3
$$

Fig. 2 SEM photographs for the system $\mathrm{Mn}_{0.58+x / 2} \mathrm{Zn}_{0.37+x / 2} \mathrm{M}_{\mathrm{x}} \mathrm{Fe}_{2.05-2 \mathrm{x}} \mathrm{O}_{4}$. 